\title{
JA für Sachgerechtigkeit und Tarifautonomie
}

\author{
Jürg Schlup \\ Dr. med., Präsident der FMH
}

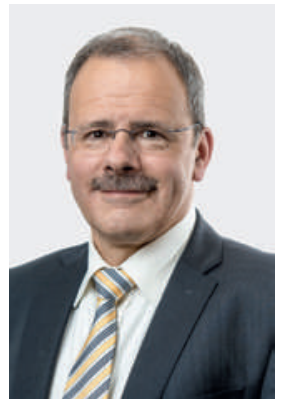

Auch wenn es bei der Ärztekammer zur Gewohnheit geworden ist, innerhalb kurzer Zeit viele wichtige - und häufig auch brisante - Themen zu diskutieren und abzustimmen, darf man doch im Rückblick auf diese Ärztekammer mit Fug und Recht behaupten, dass es sich um eine aussergewöhnliche handelte. Das wichtigste Traktandum bildete die Revision des ambulanten Tarifs und die Entscheidung, ob zu dieser Revision auch eine Urabstimmung stattfinden soll.

Dass die Revision eines ambulanten Tarifs, der auf Datengrundlagen von 1996 beruht, notwendig ist, ist unbestritten. Dass eine Revision, die relevante Kosten-

\section{Einen besseren und breiter abgestützten Tarif als den vorgeschlagenen werden wir nicht bekommen.}

steigerungen verursacht, von der Politik kaum akzeptiert würde, hat diese bereits deutlich gemacht. Dass eine Revision von Leistungsbewertungen neben Aufwertungen auch Abwertungen zur Folge hat, liegt in der Natur der Sache. Leider wird dies aber auch zur Stimmungsmache missbraucht.

Der vorliegende Vorschlag für die Tarifrevision ist das Resultat einer jahrelangen intensiven Zusammenarbeit vieler Experten aller Fachgesellschaften, die Leistung für Leistung überprüft haben. Ihr Ergebnis ist die Tarifstruktur ats-tms: eine Wertrelation der Leistungen untereinander, die dank der eingebrachten ärztlichen Expertise dem Ideal der Sachgerechtigkeit so nahe kommt wie möglich. Ihre Kritik an wichtigen Details wird in der für die Zukunft vorgesehenen, verbesserten Tarifpflege berücksichtigt werden. Aber innerhalb der engen Zeitvorgaben des Bundes werden wir keinen besseren und breiter abgestützten Tarif als den zur Abstimmung vorgelegten bekommen. Mit einer Ablehnung dieses Vorschlags würde sich die Ärzteschaft selber vom Verhandlungstisch verabschieden: Unser Einfluss auf den ambulanten Tarif wäre kleiner und wir müssten uns an wiederholte amtliche Tarifeingriffe gewöhnen. Sicher ist: Der Tarif wird sich ändern. Offen ist, ob wir als Ärzteschaft unsere Verantwortung für seine Sachgerechtigkeit wahrnehmen - oder diese an das BAG und seine Verwaltung abgeben.

Die Ärztekammer vom 28. April 2016 hat die Tarifstruktur ats-tms Version 1.0 mit klarer Mehrheit angenommen. Gleichzeitig stimmte sie aber der Normierungsvereinbarung nur unter dem Vorbehalt zu, dass die dadurch verursachten Abweichungen innert fünf bis zehn Jahren korrigiert werden. Die Normierung stellt sicher, dass die revidierte Struktur das gleiche Taxpunktvolumen wie die alte Struktur aufweist. Ohne Normierung würde die neue Tarifstruktur vom Bundesrat nicht genehmigt und von den Kostenträgern nicht akzeptiert.

Da die Ärztekammer dem Antrag des Zentralvorstands gefolgt ist, zur Revision des ambulanten Tarifs eine Urabstimmung durchzuführen, liegt die letzte Entscheidung nun bei Ihnen.

Alle ordentlichen FMH-Mitglieder sind zur Teilnahme an der Urabstimmung eingeladen. Sie erhalten per Briefpost den Stimmrechtsausweis, den Stimmzettel mit den Abstimmungsfragen, ein an das Notariat adressiertes Antwortcouvert und Informationen zu den abzustimmenden Fragen. Wer möchte, kann seinen Stimmzettel in einem verschlossenen Couvert ins Antwortcouvert legen. Der letztmögliche Einsendetermin für die Stimmabgabe ist der 28. Mai 2016 (Datum des Poststempels).

Unsere Verantwortung für einen sachgerechten Tarif nicht wahrzunehmen hiesse, sie an das BAG und seine Verwaltung abzugeben.

Eine vollständige Dokumentation sowie einen Tarifbrowser mit den revidierten Leistungspositionen finden Sie online auf myFMH. Ausserdem wird in der SÄZ vom 18.5.2016 noch ein erläuternder Artikel zur Revision erscheinen. Die ärztlichen Fachgesellschaften, unser Tarifteam, unsere Tarifpartner und weitere Experten haben viel Arbeit investiert, damit wir Ihnen diesen sachgerechten und zukunftsfähigen ambulanten Tarif anbieten können - bitte sichten Sie die Informationen und machen Sie von Ihrem Stimmrecht Gebrauch! 